\title{
OPTIMALISASI BAGI HASIL PADA PRODUK PEMBIAYAAN MUDHARABAH DALAM MENINGKATKAN LABA DAN MARKET SHARE
}

\author{
Layla Nurrachmi \\ Universitas Islam Negeri Maulana Malik Ibrahim Malang, Jl. Gajayana No. 50 Malang, \\ 65144, Indonesia \\ e-mail :nurrachmi.layla@yahoo.com
}

\author{
Zuraidah \\ Universitas Islam Negeri Maulana Malik Ibrahim Malang, Jl. Gajayana No. 50 Malang, \\ 65144, Indonesia \\ e-mail : ida.zuraidah94@yahoo.co.id
}

\begin{abstract}
Sharia in accounting are required to apply Sharia principles one is not allowed the existence of interest because it belongs in the category of usury, so that an Islamic banking system for the results, one of them on mudharabah financing, which is the core product of Sharia banking. The financial report on the statistics on Islamic banking income and market share of financing has the lowest proportion of mudharabah, optimization of products for mudharabah financing is important to increase profit and market share. This research is qualitative research by taking the location of research in PT Bank BRISyariah Malang Soekarno-Hatta. Data taken researchers use interview techniques and other secondary data, the researchers then perform data analysis and interpret the data obtained. The results of this research show that at PT Bank BRISyariah Malang branch Soekarno Hatta in applying the principle for the outcome has been in accordance with the rules of Fatwa DSN MUI No. 07/DSN-MUI/IV/2000, but Mudharabah financing is not a core product Because there are more uses for Mutanaqisah and Murabahah financing. The optimization efforts that have been done are not fully optimal, another way that can be done is to give fair incentives to customers who report their business honestly. If it can be applied then profit will increase so that the market share financing Mudarabah will also increase.

Key Words :Optimizatio; Mudharabah Financing; For The Results, Profit; Market Share
\end{abstract}

\section{Abstrak}

Dalam akuntansi syariah diharuskan menerapkan prinsip syariah salah satunya adalah tidak diperbolehkan adanya bunga karena termasuk dalam kategori Riba, sehingga dibentuklah perbankan syariah yang menggunakan sistem bagi hasil, salah satunya pada pembiayaan mudharabah, yang merupakan core product dari perbankan syariah. Laporan keuangan statistik perbankan syariah pendapatan dan market share pembiayaan mudharabah memiliki proporsi paling rendah, optimalisasi bagi hasil produk pembiayaan mudharabah penting dilakukan untuk dapat meningkatkan laba dan market share. Penelitian ini merupakan penelitian kualitatif dengan mengambil lokasi penelitian di PT Bank BRISyariah Cabang Malang Soekarno Hatta. Data yang diambil peneliti menggunakan teknik wawancara dan data sekunder lainnya, yang kemudian peneliti melakukan analisis data dan menginterpretasikan data yang diperoleh. Hasil dari penelitian ini menunjukkan bahwa pada PT Bank BRISyariah Cabang Malang Soekarno Hatta dalam menerapkan prinsip bagi Hasil telah sesuai dengan aturan Fatwa DSN MUI No.07/DSN-MUI/IV/2000, akan tetapi pembiayaan mudharabah bukan menjadi core product karena lebih banyak menggunakan pembiayaan musyarakah dan murabahah. Upaya optimalisasi yang telah dilakukan belum sepenuhnya optimal, cara lain yang dapat dilakukan adalah dengan pemberian insentif yang adil pada nasabah yang melaporkan usahanya dengan jujur. Jika hal tersebut dapat 
diterapkan maka laba akan mengalami peningkatan sehingga market share pembiayaan mudarabah juga akan meningkat.

Kata Kunci: Optimalisasi; Bagi Hasil; Pembiayaan Mudharabah;,Laba; Market Share

\section{PENDAHULUAN}

Di zaman modern saat ini lembaga keuangan bank maupun non bank banyak digunakan oleh masyarakat dalam menunjang kegiatan transaksi keuangan. Seperti kegiatan perdagangan maupun perkonomian. Hal ini sesuai dengan fungsi dari perbankan itu sendiri yaitu menghimpun dan menyalurkan dana dari dan untuk masyarakat, serta dapat mendukung kelancaran dari mekanisme pembayaran. Didalam prakteknya, dalam perbankan konvesional terdapat pembayaran bunga, hal ini dinilai sangat bertentangan dengan prinsip ajaran Islam. sehingga diperkenalkanlah perbankan syariah yang merupakan lembaga keuangan yang beroperasional berdasarkan dengan yang ada pada syariat Islam yaitu menggunakan sistem bagi hasil.

Ranang Aji (2009) menyebutkan bahwa Produk dengan sistem bagi hasil antara bank syariah dengan nasabah sebenarnya merupakan inti dari perbankan syariah yang membedakan dengan perbankan konvensional.Dengan digunakannya sistem bagi hasil pada Produk yang ditawarkan dapat memberikan suatu solusi yang menguntungkan dari kedua belah pihak yaitu dari sisi perbankan dan sisi masyarakat, karena dalam berproduksi mengutamakan nilai persaudaraan dan kebersamaan, serta dalam melakukan transaksi mengutamakan keadilan, dan menghindari suatu kegiatan yang spekulatif dalam melakukan transaksi keuangan (Bank Indonesia, 2016).

Salah satu produk yang menggunakan sistem bagi hasil adalah dari pembiayaan dengan menggunakan akad Mudharabah. Mudharabah sendiri menurut PSAK 105 ialah suatu bentuk kontrak kerja sama yang terjadi diantara pemilik dana yang disebut dengan shahibul maal dengan pengelola dana yang disebut dengan mudharib dengan menggunakan sistem bagi hasil yang sudah disetujui oleh pihak yang berakad pada saat melakukan kontrak perjanjian. Dan apabila mudharib melakukan kelalaian yang dilakukan dengan tidak sengaja maka kerugian ditanggung oleh pemilik dana (IAI,2007).

Pembiayaan mudharabah dalam perjalanannya belum memberikan suatu kontribusi yang optimal dan maksimal dalam mendukung kemajuan 
perekonomian sektor riil, karena untuk saat ini masih didominasi oleh pembiayaan murabahah yang menggunakan sistem non-bagi hasil. Berdasarkan data statistik perbankan syariah bulan Juni tahun 2018, proporsi pembiayaan untuk produk murabahah mencapai $51.77 \%$, sedangkan proporsi untuk produk pembiayaan mudharabah sebesar 5.27\%. (Statistik Perbankan Syariah,2018). Rendahnya berpengaruh pada market share dan keuntungan bersih yang diperoleh oleh perbankan syariah terutama pada produk pembiayaan mudharabah. Salah satu upaya agar dapat meningkatkan proporsi pembiayaan mudharabah yaitu dengan optimalisasi bagi hasil pada produk pembiayaan mudharabah.

Berdasarkan uraian latar belakang di atas, penelitian ini memiliki rumusan masalah, yaitu: bagaimana penerapan bagi hasil pada produk pembiayaan mudharabah pada PT Bank BRISyariah Cabang Malang Soekarno Hatta? Dan bagaimana mengoptimalkan bagi hasil pada produk pembiayaan mudharabah dalam meningkatkan laba dan market share pada PT Bank BRISyariah Cabang Malang Soekarno Hatta? Penelitian ini mengacu pada penelitian yang telah dilakukan Rosmiati,dkk (2017) yang berjudul Optimalisasi Bagi Hasil dalam Meningkatkan Laba dan market Share Produk Pembiayaan Mudharabah. Perbedaan penelitian ini dengan penelitian Rosmiati,dkk adalah pada Objek dan pendekatan penelitian yang digunakan. Tujuan dalam penelitian ini yaitu untuk dapat mengetahui penerapan bagi hasil produk pembiayaan mudharabah pada PT Bank BRISyariah dan untuk mengoptimalkan bagi hasil pada produk pembiayaan mudharabah dalam meningkatkan laba dan market share pada PT Bank BRISyariah Cabang Malang Soekarno Hatta.

\section{KAJIAN PUSTAKA}

\section{Teori Bagi Hasil}

Dalam terminologi asing, teori bagi hasil disebut juga dengan Profit And Loss Sharing (PLS). PLS merupakan keuntungan maupun kerugian yang bisa saja muncul dari suatu kegiatan bisnis atau ekonomi yang ditanggung secara bersama-sama (Yahya Muchlis.Edy Yusuf, 2011). Dalam pengertian lain profit sharing ialah bagi hasil yang dihitung berdasarkan pada pendapatan bersih yang didapat dari jumlah seluruh pendapatan dikurangi seluruh beban yang sudah 
dikeluarkan. (Rosmiati, 2017). Sehingga dapat disimpulkan bahwa bagi hasil merupakan suatu pembagian hasil usaha yang diperoleh dari pendapatan yang sebelumnya telah disepakati diawal perjanjian yang dibuat oleh pihak bank syariah dan nasabah.

\section{Bagi Hasil dalam Perspektif Islam}

Allah SWT telah menciptakan hambanya sebagai makhluk sosial agar bisa saling berkomunikasi dan adanya sifat saling membutuhkan antara individu satu dengan individu lainnya. Terdapat seseorang yang ditakdirkan untuk mempunyai materi yang lebih tetapi tidak mempunyai waktu maupun kemampuan untuk dapat mengelolanya dan mengembangkannya, namun dilain pihak terdapat seseorang yang ditakdirkan mempunyai keahlian tetapi tidak mempunyai dana. Sehingga dari adanya interaksi dua kepentingan itulah diharapkan bisa saling mempermudah kemampuan dan pengembangan harta tersebut.Dalam ajaran Islam mendorong untuk seluruh masyarakatnya dapat melaksanakan bagi hasil dan diharamkannya riba.

\section{Pembiayaan Akad Mudharabah}

Pembiayaan adalah suatu pemberian modal usaha oleh pemilik dana untuk pengelola dana agar dapat mengelolanya. Secara istilah, mudharabah ialah suatu akad kerja sama antar dua pihak, yaitu pihak pertama (shahib al-mal) yang mmemberikan seluruh modalnya secara $100 \%$, sedangkan terdapat pihak yang lain menjadi pengelola dari modal tersebut. Sehingga dapat diambil suatu kesimpulan bahwa pembiayaan dengan menggunakan akad mudharabah ialah kontrak pembiayaan yang terjadi antara bank syariah yang bertindak sebagai shahibul maal dan nasabah yang bertindak sebagai mudharib, dalam hal ini bank syariah menyerahkan modal $100 \%$ sebagai modal usaha nasabah dalam kegiatan usahanya.

\section{Laba}

Laba (penghasilan bersih) menurut IAI, (2007:13) di dalam buku “Standar Akuntansi Keuangan" ialah perolehan dari kinerja dan menjadi dasar pengukuran perolehan dari kegiatan operasional perusahaan, dan yang berkaitan dengan laba adalah pendapatan dan beban. Sedangkan laba menurut 
Kuswadi, (2006:210) “Memahami Rasio Keuangan Orang Awam" dijelaskan bahwa laba ialah pendapatan dan hasil dari penjualan yang dikurangi dengan biaya-biaya pemasaran dan pengadaan. Jadi dapat disimpulkan bahwa laba adalah ukuran kinerja perusahaan yang dilihat dari pendapatan bersih hasil penjualan baik barang maupun jasa.

\section{Laba dalam Perspektif Islam}

Dasar-dasar pengukuran laba dalam Islam: (1) Interaksi dan Risiko. Laba ialah hasil yang diperoleh dari kegiatan memutar modal dari kegiatan ekonomi. (2) Al-Muqabalah ialah membandingan seberapa besar yang diperoleh dengan seluruh pengorbanan atau biaya yang telah dikeluarkan agar memperoleh income. (3) Laba dari Kegiatan Produksi, merupakan pertambahan pada harta selama satu tahun dari seluruh kegiatan pembelian dan penjualan, atau kegiatan memproduksi dan kemudian menjualnya. (4) Perhitungan dari Nilai Barang pada Akhir Tahun, Melakukan penilaian pada persediaan barang yang masih tersedia memiliki tujuan yaitu agar dapat menghitung besarnya zakat atau dapat digunakan untuk membuat neraca keuangan.

\section{Market Share}

Market Share ialah proporsi dari kemampuan dari suatu entitas terhadap penjualan secara menyeluruh dari semua pesaing, termasuk dari penjualan entitas itu sendiri (Rosmiati, dkk. 2017). Menurut Harjito, dkk (2017) market share merupakan porsi dari kegiatan penjualan industri, baik itu dari barang maupun jasa yang mana kegiatan tersebut dikendalikan sendiri oleh perusahaan. Tingkat dari market share bisa digunakan untuk pedoman maupun standard keberhasilan bagian pemasaran dari perusahaan dimana posisi perusahaannya dengan para pesaingnya.

\section{METODE}

Penelitian ini menggunakan metode penelitian kualitatif yang bersifat analisis deskriptif. Lokasi penelitian adalah PT Bank BRISyariah Cabang Malang Soekarno Hatta dalam hal ini merupakan salah satu dari lembaga keuangan syariah dan berada di Jalan Soekarno Hatta, Kelurahan Jatimulyo, Kecamatan Lowokwaru, Kota Malang, Jawa Timur. 
Data yang digunakan oleh peneliti adalah data primer dan juga data sekunder. Data primer adalah data yang didapatkan dari hasil penelitian di lapangan melalui wawancara secara langsung peneliti dengan pihak PT Bank BRISyariah Cabang Malang Soekarno Hatta. Dan untuk data sekunder yang digunakan dalam penelitian ini ialah data berupa beberapa jurnal yang dijadikan panduan untuk dapat memahami data penelitian dan dokumen yang dijadikan bukti pendukung oleh peneliti pada saat melakukan penelitian yang didapatkan dari PT Bank BRISyariah Cabang Malang Soekarno Hatta. Sedangkan jenis data pada penelitian ini ialah berupa data kuantitatif dan data kualitatif.

Analisis data yang digunakan pada penelitian ini menggunakan metode interpretatif kualitatif. Tahapan-tahapan analisis data kualitatif model analisis interaksi, yaitu: mereduksi data (pengkodean data dan analisis dengan interpretasi teks), menyajikan data (display data), kesimpulan.

\section{HASIL DAN PEMBAHASAN}

Bagi hasil yang diterapkan pada Bank BRISyariah Cabang Malang Soekarno Hatta: pertama, kesepakatan bagi hasil dilakukan di awal terjadinya akad, hal ini sesuai dengan peraturan pada Kompilasi Hukum Ekonomi Syariah pasal 187 dalam "Buku Standar Produk Mudharabah" yang menjelaskan bahwa kesepakatan mengenai bidang usaha yang nantinya akan dijalankan ditetapkan di awal dalam akad antara kedua belah pihak yaitu antara pihak bank syariah dengan pihak nasabah (Otoritas Jasa Keuangan, 2019). Kedua, nisbah bagi hasil didasarkan pada keemampuan nasabah. Perbankan syariah seperti BRISyariah menetapkan nisbah dari bagi hasil terhadap produk pembiayaan yang dimilikinya sesuai dengan kondisi dari nasabahnya, sehingga untuk setiap nasabah bagi hasil yang didapatkan tidak akan sama. Berdasarkan hasil wawancara dengan marketing BRI Syariah Cabang Malang Soekarno Hatta Bapak Rohman pada hari Kamis Pukul 11.00 WIB diketahui bahwa:

“Dalam menentukan bagi hasil pembiayaan mudharabah dilihat dari kondisi dan keuntungan yang didapatkan oleh nasabah".

Ketiga, metode yang digunakan menggunakan revenue sharing. Dalam hasil wawancara dengan marketing BRI Syariah Cabang Malang Soekarno Hatta Bapak Rohman pada hari kamis pukul 11.35 WIB diketahui bahwa: 
"Metode perhitungan bagi hasil usaha yang digunakan dengan menggunakan revenue Sharing yaitu didasarkan pada pendapatan nasabah".

Bank BRISyariah didalam menyalurkan pembiayaannya dengan menggunakan akad mudharabah, pasti akan dihadapkan pada tingginya risiko yang dihadapi dengan timbulnya berbgai macam kendala. Sebagai usaha yang sudah dilakukan oleh bank BRISyariah untuk dapat mengoptimalkan bagi hasil pembiayaan mudharabah ialah sebagai berikut:

1. Dengan menyalurkan pembiayaan mudharabah dengan model linkage.

Berdasarkan hasil wawancara dengan marketing BRISyariah Malang Soekarno Hatta, Bapak Rohman pada hari Kamis pukul 11.05 WIB:

"untuk pembiayaan dengan akad mudharabah BRI Syariah lebih fokus untuk pembiayaan linkage".

Penerapan pembiayaan mudharabah dengan model linkage telah sesuai dengan Peraturan Menteri No. 03/per/M.KUKM/III/2009. Sehingga dapat meminimalkan risiko karena sudah memiliki legalitas usaha.

2. Menerapkan kriteria yang ketat dan melakukan screening pada kriteria usaha dan kriteria mudharib.

Untuk dapat mengoptimalkan bagi hasil cara yang dilakukan oleh Bank BRISyariah adalah dengan menerapkan kriteria yang ketat dan melakukan screening untuk kriteria nasabah maupun usaha yang nantinya akan diberikan pembiayaan, hal ini sesuai dengan penelitian Muhammad (2008:17) bahwa untuk permasalahan yang ada pada akad mudharabah dapat dikurangi dengan cara diterapkannya screening pada kriteria usaha dan kriteria pengelola dana. Dalam hasil wawancara dengan marketing Bank BRISyariah Bapak Rohman pada hari kamis pukul 11.15 WIB diketahui bahwa:

"sangat ketat dan sangat berhati-hati dalam menyeleksi calon nasabahnya yang akan memperoleh pembiayaan menggunakan akad mudharabah".

3. Melakukan Pengawasan

Dengan melakukan pengawasan pada usaha nasabah, permasalahan yang terjadi dapat diminimalisirkan. Pengawasan merupakan bentuk peringatan secara dini yang dapat mengantisipasi tanda timbulnya bentuk 
penyimpangan pada syarat-syarat yang sudah disepakati diantara shahibul maal dengan mudharib. Hal ini mendukung penelitian yang dilakukan oleh Fielnanda (2017:9) yang menjelaskan bahwa pengawasan merupakan suatu tindakan yang efektif untuk mengurangi resiko.

Pengawasan yang dilakukan oleh BRI Syariah Cabang Malang Soekarno Hatta adalah pengawasan secara berkala yang didasarkan sesuai dengan tingkat risiko pada nasabah. Hasil wawancara dengan Bapak Rohman selaku marketing BRI Syariah Cabang Malang Soekarno Hatta Malang pada hari Kamis pukul 11.30 WIB:

“iya melakukan pengawasan,misalnya satu bulan sekali atau tiga bulan sekali tergantung dari kondisi nasabah".

\section{KESIMPULAN}

Penerapan pembiayaan mudharabah dengan model linkage telah sesuai dengan Peraturan Menteri No. 03/per/M.KUKM/III/2009. Sehingga dapat meminimalkan risiko karena sudah memiliki legalitas usaha. Untuk dapat mengoptimalkan bagi hasil cara yang dilakukan oleh Bank BRISyariah adalah dengan menerapkan kriteria yang ketat dan melakukan screening untuk kriteria nasabah maupun usaha yang nantinya akan diberikan pembiayaanPengawasan yang dilakukan oleh BRI Syariah Cabang Malang Soekarno Hatta adalah pengawasan secara berkala yang didasarkan sesuai dengan tingkat risiko pada nasabah.

\section{DAFTAR PUSTAKA}

Al-Qur'an al-Karim dan terjemahan.

Bank Indonesia. (2016) Sekilas Perbankan Syariah. Diperoleh dari http://www.bi.go.id/id/perbankan/syariah/Contents/Default.aspx ,diakses pada tanggal 13 November 2018.

Fielnanda, Refky. (2017) Alternatif Solusi atas Problematika Pembiayaan Mudharabah. Jurnal Al-Ashlah, 1(1),h. 1-20.

Harjito,Yunus., Budi Utami, Dian., Indriana, dan Hapsari, Dian. (2017). Analisis Market Share Perbankan Syariah di Indonesia. Proceeding. Simposium Nasional Akuntansi XX. Jember. 17-18. 
Ikatan Akuntansi Indonesia (IAI). (2007). Exposure Draft PSAK 105.

Ismail. (2011). Perbankan Syariah (Ed. 1, Cet. ke- 1). Jakarta: Kencana Media Group.

Muhammad. (2008). Manajemen Pembiayaan Mudharabah di bank Syariah: Startegi Memaksimalkan Return dan Meminimalkan Risiko Pembiayaandi Bank Syariah sebagai Akibat Masalah Agency. Yogyakarta: Rajawali.

Otoritas Jasa Keuangan. (2018) Statistik Perbankan Syariah-Desember 2018. Diperoleh dari https://www.ojk.go.id/id/kanal/syariah/data-danstatistik, diakses pada tanggal 4 Desember 2018

.(2019). Buku Standar Produk Mudharabah. Diperoleh dari https://www.ojk.go.id/kanal/syariah/berita-dan-keuangan, diakses pada tanggal 18 Mei 2019.

Departemen Koperasi dan UMKM (2009). Pedoman Umum Linkage Program antara bank Umum dengan Koperasi. Diperoleh dari www.depkop.go.id, diakses pada tanggal 19 Mei 2019.

Rosmiati., Sumarlin., Muchlis, Saiful., Wahyuddin, dan Abdullah. M. (2017). Optimalisasi Bagi Hasil dalam Meningkatkan Laba dan Market Share Produk Pembiayaan Mudharabah, Proceeding. Simposium Nasional Akuntansi XX. Jember. h. 1-3.

Tarsidin. (2010). Bagi Hasil, Konsep dan Analisis. Jakarta: Lembaga Penerbit FEUI.

Yahya, Muchlis dan Yusuf Anggono, Edy. (2011). Teori Bagi Hasil (Profit And Loss Sharing) Perbankan Syariah dalam Ekonomi syariah. Jurnal Dinamika Ekonomi Pembangunan, Juli 2011, Vol. 1, No. 1. h. 65-73. 